Article

\title{
Investigation of Statistical Metal-Insulator Transition Properties of Electronic Domains in Spatially Confined $\mathrm{VO}_{2}$ Nanostructure
}

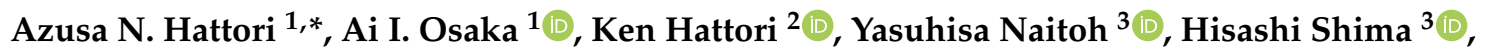 \\ Hiroyuki Akinaga ${ }^{3}$ and Hidekazu Tanaka ${ }^{1}$ \\ 1 The Institute of Scientific and Industrial Research, Osaka University, 8-1 Mihogaoka, Ibaraki, Osaka 567-0047, \\ Japan; osakaai@sanken.osaka-u.ac.jp (A.I.O.); h-tanaka@sanken.osaka-u.ac.jp (H.T.) \\ 2 Division of Materials Science, Graduate School of Science and Technology, Nara Institute of Science and \\ Technology, Takayama 8916-5, Ikoma, Nara 630-0192, Japan; khattori@ms.naist.jp \\ 3 National Institute of Advanced Industrial Science and Technology, Higashi 1-1-1, Tsukuba, Ibaraki 305-8565, \\ Japan; ys-naitou@aist.go.jp (Y.N.); shima-hisashi@aist.go.jp (H.S.); akinaga.hiro@aist.go.jp (H.A.) \\ * Correspondence: a-hattori@sanken.osaka-u.ac.jp; Tel.: +81-6-6105-6953
}

Received: 29 June 2020; Accepted: 21 July 2020; Published: 22 July 2020

\begin{abstract}
Functional oxides with strongly correlated electron systems, such as vanadium dioxide, manganite, and so on, show a metal-insulator transition and an insulator-metal transition (MIT and IMT) with a change in conductivity of several orders of magnitude. Since the discovery of phase separation during transition processes, many researchers have been trying to capture a nanoscale electronic domain and investigate its exotic properties. To understand the exotic properties of the nanoscale electronic domain, we studied the MIT and IMT properties for the $\mathrm{VO}_{2}$ electronic domains confined into a $20 \mathrm{~nm}$ length scale. The confined domains in $\mathrm{VO}_{2}$ exhibited an intrinsic first-order MIT and IMT with an unusually steep single-step change in the temperature dependent resistivity $(R-T)$ curve. The investigation of the temperature-sweep-rate dependent MIT and IMT properties revealed the statistical transition behavior among the domains. These results are the first demonstration approaching the transition dynamics: the competition between the phase-transition kinetics and experimental temperature-sweep-rate in a nano scale. We proposed a statistical transition model to describe the correlation between the domain behavior and the observable $R-T$ curve, which connect the progression of the MIT and IMT from the macroscopic to microscopic viewpoints.
\end{abstract}

Keywords: $\mathrm{VO}_{2}$; metal-insulator transition; phase separation; electronic phase; first-order transition; spatial confinement effect

\section{Introduction}

A correlated electron material (CEM) exhibits rich and fascinating properties originating from the interplay between the spin, lattice, charge, and orbital degrees of freedom of the material. Vanadium dioxide $\left(\mathrm{VO}_{2}\right)$ is one of the representative and most extensively studied CEMs [1]. $\mathrm{VO}_{2}$ displays an interesting metal-insulator transition (MIT) and insulator-metal transition (IMT) at a convenient temperature, which is accompanied by the structural phase transition. In the MIT process the high-temperature, tetragonal and metallic phase transits to the low-temperature, monoclinic and insulating phase, and in the IMT process vice versa. Figure 1 shows the temperature dependent resistivity $(R-T)$ curve for a $\mathrm{VO}_{2}$ film sample. A gradual change in resistivity, as much as three orders of magnitude, was observed in the heating and cooling processes. The transition temperature from the insulator to the metal $\left(T_{I \rightarrow M}\right)$ was $\sim 77^{\circ} \mathrm{C}$ and that from the metal to the insulator $\left(T_{M \rightarrow I}\right)$ was $\sim 65^{\circ} \mathrm{C}$. This transition has been attracting considerable interest for fundamental reasons [1,2] and possible applications [3-12] 
since the phase transition provides an abrupt change in resistivity of several orders of magnitude. Despite this strong motivation, the phase transition mechanisms cannot be addressed completely. A spatial phase inhomogeneity, i.e., phase-separation through the MIT and IMT [13-25], is the main reason hampering the understanding of the phase transition mechanism. The phase-separation could originate from the inevitable nonuniform local stress and/or chemical-composition distribution in a sample. Direct observations using the microscopic techniques showed that electronic phases are separated in a percolative manner [19,26-28].

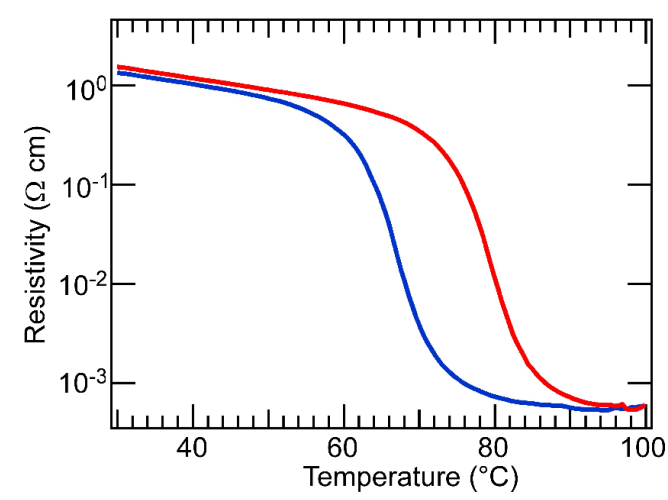

Figure 1. Temperature dependent resistivity curve for epitaxial $\mathrm{VO}_{2}$ film grown on $\mathrm{Al}_{2} \mathrm{O}_{3}(0001)$. Drastic changes in resistivity corresponding to the insulator-metal transition (IMT) and metal-insulator transition (MIT) occurs at $\sim 77^{\circ} \mathrm{C}$ and $\sim 65^{\circ} \mathrm{C}$ in the heating (red line) and cooling (blue line) processes, respectively.

Multiple phase coexistence has been observed not only in $\mathrm{VO}_{2}$, but also in many different CEMs, such as manganite [29-31] and nickelate [32-34]. The coexistence of metal and insulator domains around $T_{I \rightarrow M}$ and $T_{M \rightarrow I}$, indicates that the properties of the CEMs are dominated by competing nanoscale and/or microscale electronic phases. The evolution of the ratio of the metal (or insulator) phase, i.e., the microscopic and macroscopic dynamics, determines the electronic transport property in the system. Therefore, a quantitative evaluation of the domain dynamics, which provides a seamless picture from the nanoscale to the macroscale, is indispensable.

Many researchers have been trying to capture a nanoscale electronic domain and investigate its exotic properties. A particularly effective approach to identify the phase transition for phase-separated CEMs is to spatially confine the target materials in ultrasmall scales equal to the average size of a single domain $[18,26,35,36]$. In the phase separation in the macrosize samples, such as $\mathrm{VO}_{2}$ thin films, metallic and insulating domains with a huge difference in conductivity are randomly mixed; the domains have a fractal nature near the transition temperatures. The percolation model can describe the transition behavior, namely, the relationship between the conductivity and the fraction of metal domains: $P_{M e t}[19,26-28]$. The counterpart of $P_{M e t}$, the occupation probability of the insulator phase: $P_{\text {Ins }}$ is defined as $P_{\text {Ins }}=1-P_{\text {Met }}$. The isotropic two-dimensional (2D) square-lattice percolation model can be applied for the thin film sample. The abrupt decrease and increase of the resistivity at $P_{\text {Met }} \sim 0.6$ and $P_{\text {Met }} \sim 0.4\left(=P_{\text {Ins }} \sim 0.6\right)$ was reported in heating and cooling process, respectively, which correspond to the formation of the connection of metallic and insulating path between electrodes [19,26-28]. Thus, for a macrosize sample, the $R$ - $T$ curve shows huge but gradual change. In this manner, $T_{I \rightarrow M}$ and $T_{M \rightarrow I}$ are defined as temperatures at $P_{M e t} \sim 0.6$ and $P_{\text {Ins }} \sim 0.6$, respectively.

On the other hand, the discrete $T_{I \rightarrow M}$ and $T_{M \rightarrow I}$ were observed on the microsize sample whose size were close to the electric domains $[13,17,18,20,26,37,38]$. The size of the formed domains varies from the order of $100 \mathrm{~nm}$ on $\mathrm{Al}_{2} \mathrm{O}_{3}$ single-crystal substrates $[17,18]$ to the order of $10 \mu \mathrm{m}$ on $\mathrm{TiO}_{2}(001)$ substrates $[13,19,20]$. The generation and extinction of the electronic domains can be attributed to nucleation, which initiates first-order phase transitions. Although there have been significant advances in understanding the general nature of the transition, the mechanism responsible for the domain generation, i.e., nucleation, is not yet well established. The nucleation rate and corresponding resistivity 
behavior strongly depend on the temperature $(T)$ sweep conditions $[39,40]$ and sample size [39-41]. However, the examination of the possible role of the temperature and sample size has been limited. A more complete understanding of these features associated with the phase-separation phenomena is indispensable to the advancement of our knowledge of the detailed physics of the phase transition in $\mathrm{VO}_{2}$. In this article, we investigate the domain dynamics in spatially confined $\mathrm{VO}_{2}$ samples. The advantage of nano-confined sample is the quantification of the domain generation (nucleation) process. An analysis based on the statistical transition model revealed the correlation between the domain size and the $T_{I \rightarrow M}$ and $T_{M \rightarrow I}$ distribution, which can explain the macroscopic progression of the IMT and MIT.

\section{Materials and Methods}

$\mathrm{A} \mathrm{VO}_{2}$ thin film with a thickness of $50 \mathrm{~nm}$ was deposited on a commercial $\mathrm{Al}_{2} \mathrm{O}_{3}(0001)$ substrate by pulsed laser deposition (PLD) (ArF excimer: wavelength of $193 \mathrm{~nm}$ ) using a $\mathrm{V}_{2} \mathrm{O}_{5}$ sintered ceramic target, as reported elsewhere [18]. The base pressure in the PLD chamber was less than $2 \times 10^{-6} \mathrm{~Pa}$. The deposition was performed under an oxygen pressure of $1 \mathrm{~Pa}$ at $350{ }^{\circ} \mathrm{C}$ with an energy density of $\sim 2 \mathrm{~J} \mathrm{~cm}^{-2}$ and a pulse repetition rate of $2 \mathrm{~Hz}$.

To observe the structural change of the $\mathrm{VO}_{2}$ film with the temperature, temperature-dependent crystal structure of the $\mathrm{VO}_{2}$ film was confirmed by reflection high-energy electron diffraction (RHEED: R-DEC RDA-003G, Tsukuba, Ibaraki, Japan) and X-ray diffraction (XRD: Rigaku SmartLab, Akishima, Tokyo, Japan). In-situ RHEED observation in the PLD chamber was performed at $2 \times 10^{-6} \mathrm{~Pa}$ in the temperature range from $30^{\circ} \mathrm{C}$ to $100^{\circ} \mathrm{C}$. Before the RHEED observation, the $\mathrm{VO}_{2}$ film was cooled to $30^{\circ} \mathrm{C}$. RHEED patterns were observed using an electron beam of $15 \mathrm{keV}$ energy and $\sim 1 \mathrm{~mm}$ diameter. These patterns were filtered using an image software program to emphasize spot features. $\theta-2 \theta$ scans were performed in an ex-situ XRD system with $\mathrm{Cu} \mathrm{K} \alpha 1$ radiation with a $\mathrm{Ge}(220)$ monochromator and a sample heating stage. The temperature sequences was $120^{\circ} \mathrm{C} \rightarrow 90^{\circ} \mathrm{C} \rightarrow 80^{\circ} \mathrm{C} \rightarrow 70{ }^{\circ} \mathrm{C} \rightarrow 60^{\circ} \mathrm{C} \rightarrow 50{ }^{\circ} \mathrm{C} \rightarrow 20^{\circ} \mathrm{C}$.

After the RHEED and XRD measurements, $\mathrm{VO}_{2}$ wire structures with a width $(W)$ of 0.6-2.0 $\mu \mathrm{m}$ were produced using a lithographic technique. The $\mathrm{VO}_{2}$ film was etched by reactive ion etching (RIE: Samco RIE-10NR, Kyoto, Kyoto, Japan) in $\mathrm{SF}_{6}$ gas, employing a photoresist mask. The optimized RIE conditions were $10 \mathrm{sccm} \mathrm{SF}_{6}, 1 \mathrm{~Pa}$, and $60 \mathrm{~W}$. In order to measure the temperature-dependent dc transport property of the $\mathrm{VO}_{2}$ samples, a pair of Au electrodes with a gap length $(L)$ of $20 \mathrm{~nm}$ or $2 \mu \mathrm{m}$ were attached to the $\mathrm{VO}_{2}$ wires. The electrodes with $L=20 \mathrm{~nm}$ were produced through the two-times tilted $\mathrm{Au} / \mathrm{Ti}$ deposition technique in accordance with previous reports [40,42]. The sample structure was confirmed by field-emission scanning electron microscopy (SEM: JEOL JSM7610F, Akishima, Tokyo, Japan). The temperature dependent resistivity $(R-T)$ measurements were carried out for the $\mathrm{VO}_{2}$ wire samples with heating and cooling in $0.1^{\circ} \mathrm{C}$ steps with temperature-sweep-rates of $0.5,2$, and $3^{\circ} \mathrm{C} / \mathrm{min}$. As a reference, $R-T$ measurements of a $\mathrm{VO}_{2}$ film $(8 \mathrm{~mm} \times 10 \mathrm{~mm} \times 50 \mathrm{~nm})$ were also performed. $T_{I \rightarrow M}$ and $T_{M \rightarrow I}$ for the film sample are calculated from the peak of $\mathrm{d}(\log R) / \mathrm{d} T$ vs. $T$ plot of the heating and cooling curves, respectively.

The $R$ - $T$ curves for the samples were simulated using the random resistor network model $[18,26,35]$. The net resistivity of the system, $R_{\text {sample }}$, was evaluated by the cycle current equation,

$$
H R H^{T} I=H V
$$

where $H$ is a cycle basis matrix, $R$ is a resistance matrix, $I$ is a current vector, and $V$ is a voltage vector, on the basis of the Kirchhoff's laws [43]. For three-dimensional (3D) cubic lattice with a resistor on each edge, $R$ is a diagonal matrix where each element is the edge $(q)$ resistance. Elements of $I$ and $V$ correspond to a loop current and applied voltage in possible closed loop (cycle $p$ ) circuits. $H$ is the matrix of the cycle number by the edge number; the element is defined as +1 (flow directions of cycle $p$ and edge $q$ are the same), -1 (opposite), or 0 (cycle $p$ does not contain edge $q$ at resistor $q$ ). The model of the $3 \mathrm{D}$ resistor network with two side electrodes with applied voltage $V_{0}$ and current $I_{0}$ leads to $R_{\text {sample }}=V_{0} / I_{0}$. 
The number of the domains, leading to the edge resistance, in 3D sample is defined as $N_{D}=$ $N_{L} \times N_{W} \times N_{H}$. The numbers of domains in the length, width, and height directions are defined as $N_{L}=L / D_{\text {ave }}, N_{W}=W / D_{\text {ave }}$, and $N_{H}=H / D_{\text {ave }}$, respectively. $D_{\text {ave }}$ is the mean domain size. Since the deposited $\mathrm{VO}_{2}$ thickness of $50 \mathrm{~nm}$ is enough smaller than the reported $D_{\text {ave }}$ [17], the calculations were performed using a 2D resistor network with $N_{H}=1$. The population of metallic domains at each temperature: $P_{\text {Met }}(T)$ was given by a Gaussian function. The metal and insulator domain arrangement in $N_{L} \times N_{H}$ domain geometry, i.e., either a metal or insulator at the $(i, j)$ site $\left(i=1 \cdots N_{L}, j=1 \cdots N_{W}\right)$ is randomly selected according to $\mathrm{P}_{\mathrm{Met}}(T)$. No interaction among the domains was considered.

\section{Results and Discussion}

\subsection{Phase-Separated $\mathrm{VO}_{2}$ Structure}

XRD and RHEED results showed that an epitaxial $\mathrm{VO}_{2}$ film was grown on the $\mathrm{Al}_{2} \mathrm{O}_{3}(0001)$ substrate. Figure 2a shows the XRD $\theta-2 \theta$ scan for the $\mathrm{VO}_{2}$ film at $20^{\circ} \mathrm{C}$. The strong reflections from the $\mathrm{VO}_{2}(020)$ and $\mathrm{VO}_{2}(040)$ planes at $2 \theta=39.9^{\circ}$ and $86.1^{\circ}$, respectively, indicate $\mathrm{VO}_{2}$ growth on the $\mathrm{Al}_{2} \mathrm{O}_{3}(0001)$ substrate with its (010) plane parallel to the substrate surface [44]. Figure $2 \mathrm{~b}$ shows the $\mathrm{VO}_{2}(020)$ peak at various temperatures. With decreasing temperature from $120^{\circ} \mathrm{C}$ to $20^{\circ} \mathrm{C}$, the peak position shifted toward a higher angle. The estimated lattice constant $b$ is plotted against temperature in Figure 2c. The lattice constant $b$ rapidly changed from $4.518 \AA$ at $80^{\circ} \mathrm{C}$ to $4.512 \AA$ at $50^{\circ} \mathrm{C}$, that is, the thermal expansion coefficient was $\sim 4 \times 10^{-4}{ }^{\circ} \mathrm{C}^{-1}$, while the thermal expansion coefficient was only $\sim 7 \times 10^{-6}{ }^{\circ} \mathrm{C}^{-1}\left(\sim 1 \times 10^{-5}{ }^{\circ} \mathrm{C}^{-1}\right)$ below $50^{\circ} \mathrm{C}$ (above $\left.80^{\circ} \mathrm{C}\right)$. This irregular thermal expansion has been established as a characteristic of the phase transition of $\mathrm{VO}_{2}$ [45]. The thermal expansion of the $\mathrm{Al}_{2} \mathrm{O}_{3}$ substrate in the $c$ direction, was $\sim 6 \times 10^{-6}{ }^{\circ} \mathrm{C}^{-1}$, as shown in the inset of Figure $2 \mathrm{c}$, which is consistent with the value of $5 \times 10^{-6}{ }^{\circ} \mathrm{C}^{-1}$ ( $c$ direction) for the $\mathrm{Al}_{2} \mathrm{O}_{3}$ single crystal [46] within the experimental error. Thus, Figure $2 c$ clearly indicates the structure transition from rutile $\mathrm{VO}_{2}\left(\mathrm{P}_{2} / \mathrm{mmm}\right)$ at a high temperature to monoclinic $\mathrm{VO}_{2}\left(\mathrm{P}_{1} / \mathrm{c}\right)$ at a low temperature [16]. The temperature dependence of the lattice constant indicates that during the phase transition in the cooling process, the initial state is rutile at $T \geq 90^{\circ} \mathrm{C}$, which is followed by a coexisting rutile/monoclinic state at $50^{\circ} \mathrm{C}<T<80^{\circ} \mathrm{C}$ and a monoclinic state at $T \leq 50^{\circ} \mathrm{C}$.

RHEED patterns directly reveal the coexisting states in $\mathrm{VO}_{2}$ through the phase transition. Figure 3a shows a typical $[\overline{2} 110]_{\mathrm{Al}_{2} \mathrm{O}_{3}}$-incident $\mathrm{RHEED}$ pattern from $\mathrm{VO}_{2}$ at $70^{\circ} \mathrm{C}$. The diffraction pattern consisted of two phases with different periodicities in the $[01 \overline{1} 0]_{\mathrm{Al}_{2} \mathrm{O}_{3}}$ direction. The most prominent diffraction peaks of one phase are noted by $(020)_{r},(040)_{r},(031)_{r},(051)_{r},(022)_{r}$, and $(042)_{r}$ which are also indicated by pink arrows; these peaks have a period of $2.2 \AA^{-1}$ in the in-plane direction, which corresponds to the reciprocal lattice unit, $c_{r}^{*}=2 \pi / c_{r}=2.20 \AA^{-1}$, along the $c$ axis of the rutile $\mathrm{VO}_{2}$ phase. At a different incident azimuth angle, $[01 \overline{1} 0]_{\mathrm{Al}_{2} \mathrm{O}_{3}}$-incident RHEED patterns (not shown) indicated diffraction peaks with a period of $1.4 \AA^{-1}$ corresponding to $a_{r}^{*}=1.38 \AA^{-1}$. Thus, the crystalline orientation relationship of the prominent phase at higher temperatures is rutile $\mathrm{VO}_{2}$ (010)[100] $\| \mathrm{Al}_{2} \mathrm{O}_{3}$ $(0001)\langle\overline{2} 110\rangle$ (Figure 3c), as reported in Ref. [44]. The other phase had a shorter in-plane periodicity (1.3-1.4 $\left.\AA^{-1}\right)$ at the $[\overline{2} 110]_{\mathrm{Al}_{2} \mathrm{O}_{3}}$ incidence, as shown by cyan arrows in Figure 3a. This phase is ascribed to monoclinic $\mathrm{VO}_{2}(010)[001]$ (or [100]) $\| \mathrm{Al}_{2} \mathrm{O}_{3}(0001)\langle 2110\rangle$ (Figure 3b) because the reciprocal lattice units, $a_{m}^{*}=1.30 \AA^{-1}$ and $c_{m}^{*}=1.39 \AA^{-1}$, correspond to the shorter periodicity in RHEED (Figure 3a). Some diffraction peaks are noted as $(350)_{m},(360)_{m}$, and $(430)_{m}$ (or $(053)_{m},(063)_{m}$, and $\left.(034)_{m}\right)$. Since XRD showed monoclinic $\mathrm{VO}_{2}[010] \| \mathrm{Al}_{2} \mathrm{O}_{3}$ [0001] (Figure 2), one can see the epitaxial $\mathrm{VO}_{2}(010)$ growth on $\mathrm{Al}_{2} \mathrm{O}_{3}(0001)$. The key point of the structural transformation between rutile and monoclinic $\mathrm{VO}_{2}$ observed in XRD and RHEED is not gradual with homogeneous changes, but comprises partial generations of drastic change from rutile to monoclinic with the spatial coexistence of the two phases, that is, phase-separated structure. This observation indicates that the gradual resistance change 
observed in an $R$ - $T$ curve (Figure 1) is associated with the propagation of the local crystallographic transformation, which is consistent with previous studies [37,47].
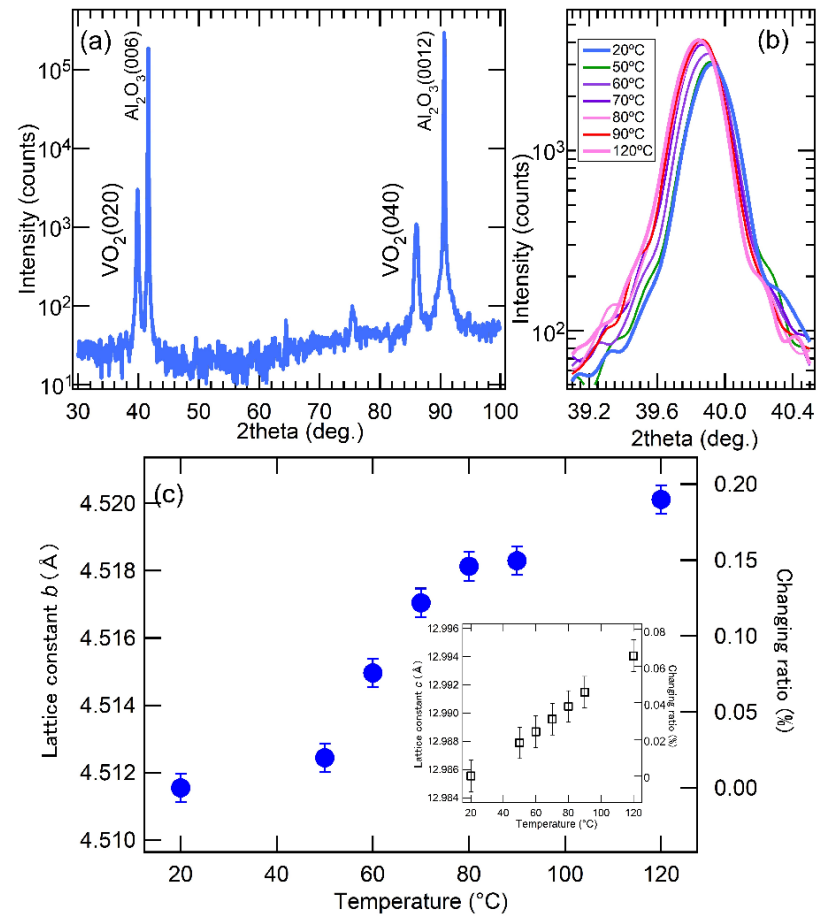

Figure 2. (a) XRD $\theta-2 \theta$ scan for $\mathrm{VO}_{2}$ film on $\mathrm{Al}_{2} \mathrm{O}_{3}(0001)$ substrate at $20^{\circ} \mathrm{C}$. (b) $\mathrm{VO}_{2}(020)$ diffraction peak at various temperatures. (c) Temperature-dependent lattice constant $b$ of the $\mathrm{VO}_{2}$ film. The inset shows the lattice constant $c$ of $\mathrm{Al}_{2} \mathrm{O}_{3}$, which monotonically increases with temperature. A small peak at $\sim 75^{\circ}$ in (a) corresponds to Ni alloys in the sample holder.
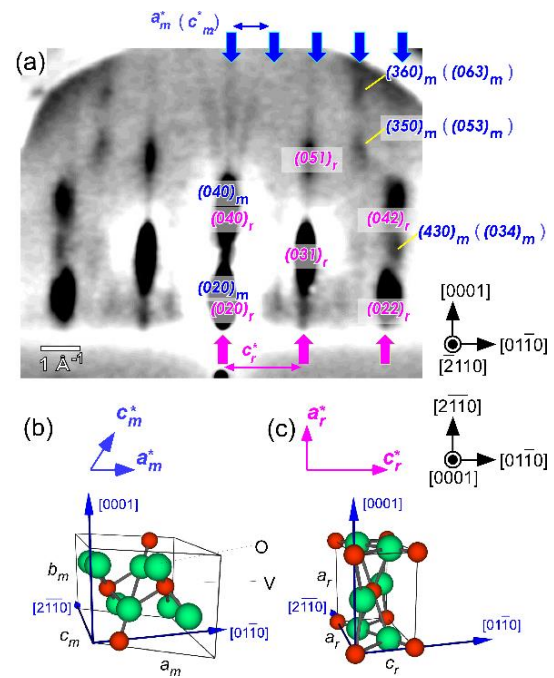

Figure 3. (a) Typical reflection high-energy electron diffraction (RHEED) pattern of $\mathrm{VO}_{2}$ film observed at $70{ }^{\circ} \mathrm{C}$. The incident electron beam direction was $[\overline{2110}]_{\mathrm{Al}_{2} \mathrm{O}_{3}}$. The spots indicated by blue and pink reflections (and arrows) correspond to the monoclinic and rutile $\mathrm{VO}_{2}$ phases, respectively. Schematic two-dimensional (2D) reciprocal lattice unit vectors on (0001) ${ }_{\mathrm{Al}_{2} \mathrm{O}_{3}}$ (top panel) and real-space crystal structures (bottom panel) for (b) monoclinic and (c) rutile $\mathrm{VO}_{2}$ phases. The crystalline orientation relationships of monoclinic and rutile $\mathrm{VO}_{2}(010)$ to $\mathrm{Al}_{2} \mathrm{O}_{3}(0001)$ are visualized with blue arrows representing $\mathrm{Al}_{2} \mathrm{O}_{3}[01 \overline{1} 0],[\overline{2} 110]$, and [0001]. 


\subsection{Transport Properties in the Phase-Separated $\mathrm{VO}_{2}$}

For phase-separated materials, by utilizing the spatial confinement effect, it is possible to isolate individual contributions from specific interactions through their inherent length scale $[35,36]$. To realize the nano-confinement effect, a pair of $\mathrm{Au} / \mathrm{Ti}$ electrodes with a gap length of $20 \mathrm{~nm}$ was attached along the length of a $\mathrm{VO}_{2}$ wire as shown in Figure $4 \mathrm{a}$,b shows a typical $R$ - $T$ curve from the $\mathrm{VO}_{2}$ wire sample with $W$ of $600 \mathrm{~nm}$ and $L$ of $20 \mathrm{~nm}$. Interestingly, one-step rapid resistivity changes were observed in both the heating and cooling processes, in contrast to the continuous changes in a macroscopic $\mathrm{VO}_{2}$ film sample (Figure 1). These one-step resistivity changes indicate the occurrence of the nano-confinement effect; the isolation of a single domain into a nano-space of $600 \mathrm{~nm} \times 20 \mathrm{~nm}$ was realized. Although the $\mathrm{VO}_{2}$ wire sample with the nano-gap electrodes showed one-step resistance changes, their change ratio through IMT and MIT was smaller than those in the film sample, which is mainly because of the unintended damages during dry etching process. However, the one-step change which is absent in the macrosize sample clearly showed that this sample exhibit a prototype of first order transition.
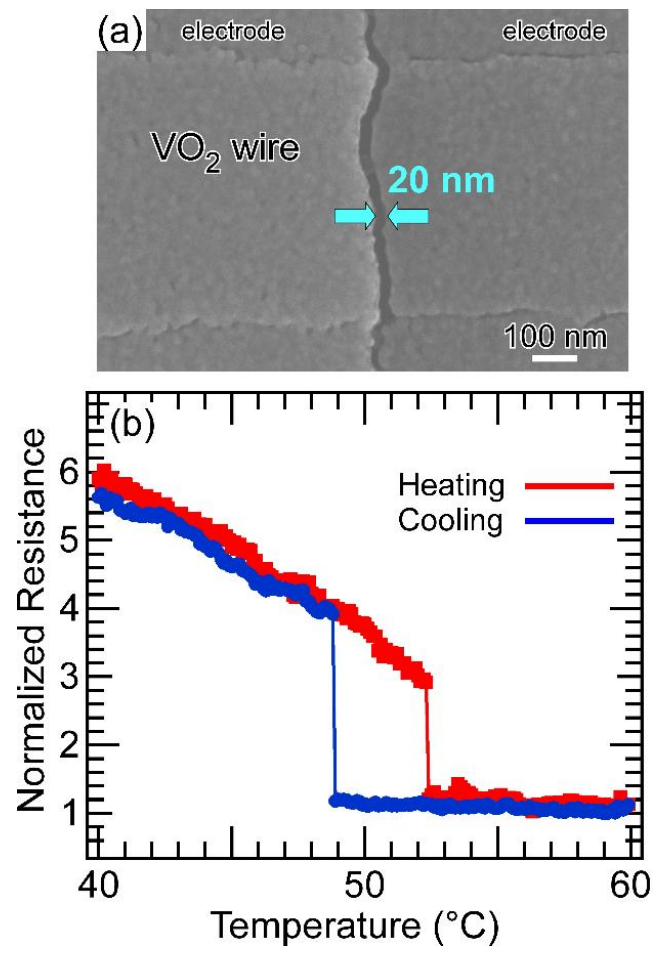

Figure 4. (a) Typical SEM image of $\mathrm{VO}_{2}$ wire with width of $600 \mathrm{~nm}$ after depositing a pair of $\mathrm{Au} / \mathrm{Ti}$ electrodes. The gap distance of the electrodes was $20 \mathrm{~nm}$, which corresponds to the $\mathrm{VO}_{2}$ region for the electronic resistivity measurement. (b) Normalized $R-T$ curve for the $\mathrm{VO}_{2}$ wire with 20 nm-gap electrodes. One-step changes in resistivity were observed in both the heating (red) and cooling (blue) processes. The resistivity was normalized by the value at $60^{\circ} \mathrm{C}$. The temperature-sweep-rate was $3.0^{\circ} \mathrm{C} / \mathrm{min}$.

$\mathrm{VO}_{2}$ undergoes a MIT and IMT accompanied by a structural transition: from a high-symmetry, metallic rutile phase at to a low-symmetry insulating monoclinic phase with $\mathrm{V}-\mathrm{V}$ dimerization in cooling (MIT) process and vice versa in heating (IMT) process [2]. The IMT in $\mathrm{VO}_{2}$ is understood by the collapse of an insulating state (electron crystal) to a metallic state (electron liquid). This is a simple picture for a nano-scale single domain. The observation of the step changes in resistivity due to the spatial confinement effect shows that the single domain has an ideal first-order IMT and MIT with one-step resistivity change. Therefore, the ensemble of the step IMTs and MITs in a macrosize sample, where the IMT and MIT in numerous domains contributes to the observable IMT and MIT as an $R-T$ 
curve, should show a gradual resistivity change without step changes as shown in Figure 1. Such a spatial distribution of the metal and insulator domains is illustrated in Figure 5a.

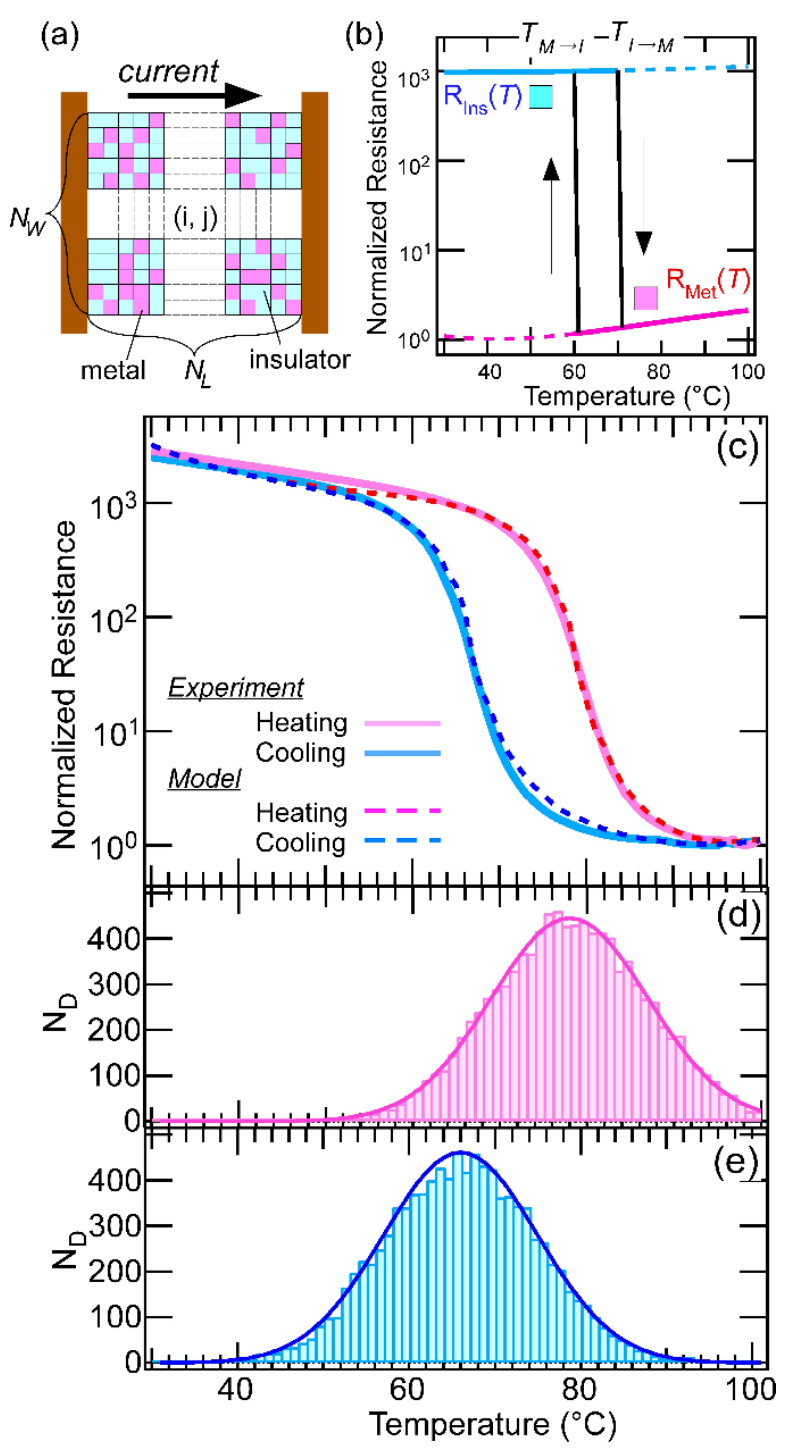

Figure 5. (a) Schematic of the phase-separated $\mathrm{VO}_{2}$ with $\left(N_{L} \times N_{W}\right)$ domain geometry: metal (pink) and insulator (cyan) phases coexist between the electrodes. (b) Ideal $R$ - $T$ curves through the IMT and MIT for a single domain with $T_{I \rightarrow M}$ of $70^{\circ} \mathrm{C}$ and $T_{M \rightarrow I}$ of $60^{\circ} \mathrm{C}$, respectively. (c) Comparison between the observed $R$-T curve for the $\mathrm{VO}_{2}$ sample (solid lines) and the simulated one using Equation (1) (dashed line). Estimated $N_{D}$ values in (d) IMT and (e) MIT processes with $T_{I \rightarrow M}=77^{\circ} \mathrm{C}$ and $T_{M \rightarrow I}=65^{\circ} \mathrm{C}$, respectively.

To consider the phase-separated condition quantitatively, we have proposed the statistical transition model $[18,35]$, where the IMT and MIT property of a single domain, the number of domains $N_{D}$, in the sample, and their statistical behavior, that is, the $T_{I \rightarrow M}$ and $T_{M \rightarrow I}$ distribution, are taken into account. The step resistivity change reflects the IMT and MIT from a single domain, showing the ideal first-order transition. Figure $5 \mathrm{~b}$ shows the ideal $R$ - $T$ curve for a $\mathrm{VO}_{2}$ single domain through the IMT and MIT. For example, in the heating (cooling) process, the domain has two transport properties defined as $\mathrm{R}_{\text {Ins }}(T)$ and $\mathrm{R}_{\text {Met }}(T) ; R_{\text {Ins }}(T)$ switches with $\mathrm{R}_{\text {Met }}(T)$ at $T_{I \rightarrow M}\left(\mathrm{R}_{\text {Met }}(T)\right.$ switches with $\mathrm{R}_{\text {Ins }}(T)$ at 
$\left.T_{M \rightarrow I}\right)$. Therefore, assuming the simplest first-order IMT and MIT, the resistivity of a single domain $\mathrm{R}_{\mathrm{S}}(T)$ is described as

$$
R_{s}(T)=\left\{\begin{array}{rlrl}
R_{I n s}(T) & =A T \exp \left(\frac{E_{g}}{k_{B} T}\right) & \left(T>T_{M I}: \text { insulating region }\right) \\
R_{\text {Met }}(T) & =R_{0}+B T^{2}+C T^{5} & & \left(T \leq T_{M I}: \text { metallic region }\right)
\end{array},\right.
$$

where $R_{I n s}(T) \gg R_{M e t}(T)$. A, B, and C are coefficients, $R_{0}$ is the residual resistivity in the metallic phase, $E_{g}$ is the activation energy in the insulating (semiconducting-like) phase, and $k_{B}$ is the Boltzmann constant. The parameters in Equation (2) were obtained by fitting for an $R-T$ curve for a film sample.

In the temperature-induced IMT of $\mathrm{VO}_{2}$, metal domains initially nucleate at seed sites in a sample, then grow and spread with increasing temperature. The domain dynamics, i.e., the temperaturedependent population of the metal domains, strongly affects the observable transport property of the sample. To express the phase-separated condition as domain dynamics, the $T_{I \rightarrow M}$ and $T_{M \rightarrow I}$ distribution is defined in this model. The direct observation of the coexistence of metal and insulator domains in the vicinity of the observable $T_{I \rightarrow M}$ and $T_{M \rightarrow I}$ [13-25] indicates that the $T_{I \rightarrow M}$ and $T_{M \rightarrow I}$ values of the single domains are distributed. The distribution of $T_{I \rightarrow M}$ and $T_{M \rightarrow I}$ for each domain can be described using the Gaussian function as

$$
f(T)=\frac{1}{\sqrt{2 \pi \sigma^{2}}} \exp \left[-\frac{\left(T-T_{\text {center }}\right)^{2}}{2 \sigma^{2}}\right],
$$

where $\sigma$ is the half width of the Gaussian distribution and $T_{\text {center }}$ is the temperature where the population of metal domains, $P_{\text {Met }}$ is equal to that of insulator domains, $P_{\text {Ins }}$, i.e., $P_{\text {Met }}\left(T_{\text {center }}\right)=P_{\text {Ins }}\left(T_{\text {center }}\right)=50 \%$. $\mathrm{f}(T)$ gives the probability of the IMT and MIT at a certain temperature. Here, the values of $\sigma$ and $T_{\text {center }}$ in the heating process are treated to be different from those in the cooling process [48]. Thus, the metal population is obtained as

$$
P_{\text {Met }}(\mathrm{T})=N_{D} \cdot \mathrm{f}(T)=1-P_{\text {Ins }}(T) .
$$

Here, we treat the resistor network with the edge resistor having the single domain resistivity $R_{S}(T)$ in Equation (2) under Equations (3) and (4), and obtain $R_{\text {sample }}(T)$ from the cycle current equation in Equation (1).

Three-dimensional (3D) cubic-lattice networks are treated for films thicker than a metal and insulator domain size; the domain size in a $\mathrm{VO}_{2}$ film on an $\mathrm{Al}_{2} \mathrm{O}_{3}$ substrate was reported to be $\sim 100 \mathrm{~nm}$ [17]. Since the thickness of the $\mathrm{VO}_{2}$ samples in this study was $50 \mathrm{~nm}$, we can treat a $2 \mathrm{D}$ square-lattice network with the number of the domains $N_{D}=N_{L} \times N_{W} \times N_{H}(=1)$. Figure 5 c shows a comparison between the observed and simulated $R-T$ curves for the $\mathrm{VO}_{2}$ film. Here, the resistivity was calculated from Equations (1)-(4) assuming $N_{L}=N_{W}=100$. The dashed curves in Figure 5c showed the good fitting of the results with this model, where the $T_{I \rightarrow M}\left(T_{M \rightarrow I}\right)$ distribution as shown in Figure $5 \mathrm{~d}$ (Figure 5e) was obtained. The good agreement between the experimental and simulation results indicates the validity of this model. This means that the observable $R-T$ property of $\mathrm{VO}_{2}$ is determined by three elements: the resistivity of a single domain $R_{S}(T)$, the $T_{I \rightarrow M}$ and $T_{M \rightarrow I}$ distributions, and the $N_{D}$ of the sample. It was reported that the MIT and IMT characteristics including the width of the hysteresis loop in a $R-T$ curve depend on various structural parameters, such as external and internal stresses, grain size in a $\mathrm{VO}_{2}$ sample since the phase transition in $\mathrm{VO}_{2}$ is coupled to the defect concentration and the types of crystal defects $[37,38,47]$. Therefore, $R_{S}(T)$ and the $T_{I \rightarrow M}$ and $T_{M \rightarrow I}$ distributions are characteristics of an individual samples that depend on its growth conditions. On the other hand, we can tune $N_{D}$ by controlling the sample size. The step resistivity changes shown in Figure $4 \mathrm{~b}$ have been observed due to the nano-confinement effects not only in $\mathrm{VO}_{2}$ but also in other CEMs $[13,18,26,35]$. The minimization of the sample size results in the step resistivity change at the stochastic $T_{I \rightarrow M}$ and $T_{M \rightarrow I}$ corresponding to the reduction in $N_{D}$. The observed $T_{I \rightarrow M}\left(T_{M \rightarrow I}\right)$ of $52{ }^{\circ} \mathrm{C}$ $\left(49^{\circ} \mathrm{C}\right.$ ) for the $\mathrm{VO}_{2}$ wire sample with $W$ of $600 \mathrm{~nm}$ and $L$ of $20 \mathrm{~nm}$ (Figure $4 \mathrm{~b}$ ) was lower than that 
of $77^{\circ} \mathrm{C}\left(65^{\circ} \mathrm{C}\right)$ for the film sample (Figure 1). The statistical model shows that $T_{I \rightarrow M}\left(T_{M \rightarrow I}\right)$ were distributed within a range of 50 to $100^{\circ} \mathrm{C}\left(40\right.$ to $\left.90^{\circ} \mathrm{C}\right)$ as shown in Figure $5 \mathrm{~d}$ (Figure 5e). The stochastic selection of a single domain as a result of the spatial confinement determined the $T_{I \rightarrow M}$ and $T_{M \rightarrow I}$ for the $20 \mathrm{~nm}$-gap wire sample while $T_{I \rightarrow M}\left(T_{M \rightarrow I}\right)$ is defined as a temperature at $P_{\text {Met }}\left(P_{\text {Ins }}\right) \sim 0.6$ for the macrosize sample with a high $N_{D}$. The isolation of one or a few domains into the nanospace makes it possible to investigate the potentially hidden domain behavior in a macrosize sample with a high $N_{D}$. Thus, the correlation between the domain size and the $T_{I \rightarrow M}$ and $T_{M \rightarrow I}$ distribution in the spatially confined structure was examined.

\subsection{Domain Dynamics of $\mathrm{VO}_{2}$ Domains: The Effect of the Temperature-Sweep-Rate}

Figure 6 shows $R$ - $T$ curves for the $\mathrm{VO}_{2}$ sample with different temperature-sweep-rate with $W$ of $0.6 \mu \mathrm{m}$ and $L$ of $20 \mathrm{~nm}$. We can see the variation of the transition behavior with the temperature-sweep-rate. At the high temperature-sweep-rate of $3{ }^{\circ} \mathrm{C} / \mathrm{min}$, the $R$ - $T$ curve showed one-step resistivity changes in both the cooling and heating processes, indicating that $N_{D}=1$ during the IMT and MIT. Interestingly, at the temperature-sweep-rate of $2{ }^{\circ} \mathrm{C} / \mathrm{min}$ (Figure $6 \mathrm{~b}$ ), multi-step resistivity changes, that is, multiple points in the transient stage in the cooling process, were observed while the one-step resistivity change was maintained in the heating process. The $R$ - $T$ curves at the temperature-sweep-rate of $0.5^{\circ} \mathrm{C} / \mathrm{min}$ consisted of the many small step changes, as shown in the insets (Figure 6c). These results clearly showed that reducing of the temperature-sweep-rate induced the multi-step resistivity changes. The change from one-step to multi-step resistivity changes indicates an increase in the $N_{D}$ of the sample, i.e., a decrease in domain size. Our observed tendency is consistent with previous reports. Lopez et al. reported the effect of sample size on $T_{I \rightarrow M}$ and $T_{M \rightarrow I}$ for $\mathrm{VO}_{2}$ nanoparticles [41], where an increase (decrease) in $T_{I \rightarrow M}\left(T_{M \rightarrow I}\right)$ with sample miniaturization was observed. They considered that the size dependence is associated with the nucleation statistics where the density of nucleating defects is a power function of the driving force for the MIT and IMT. Yoon et al. found an effect of size on the phase transition speed [39]; the transition speed was roughly proportional to $1 / w$, where $w$ is the width of the $\mathrm{VO}_{2}$ microcrystal. They pointed out the possibility of size-dependent thermal dissipation. Oike et al. reported size-dependent supercooling phenomena in strongly correlated electron systems and suggested a nucleation mechanism [40]. In general, systematic shifts of $T_{I \rightarrow M}$ $\left(T_{M \rightarrow I}\right)$ toward high (low) temperatures when increasing temperature-sweep-rate are observed, implying that nucleation events are involved in the first-order transition [49]. Namely, the nucleation rate of the electronic domains is consistent with the generation speed of the operational defects in the sample $[38,40,47]$. Thus, we can expect the phenomena based on the nucleation mechanism [40]. Most first-order phase transitions are initiated by nucleation, which is a critical rate event. The first-order transition could be kinetically suppressed under sufficient rapid cooling or heating; the nucleation growth rate of the domains leading to the first-order transitions is slow compared with the external temperature-sweep-rate. The most extensively studied realization of this scenario is classical liquids [50]. Extension of this manner will be applicable for the IMT and MIT in $\mathrm{VO}_{2}$.

In the frame of this phase-separated scenario, an increase of the transition (nucleation) sites is described as an increase in $N_{D}$ with decreasing the mean domain size: $D_{\text {ave }}$ under the slow temperature-sweep-rate. The nucleation of metal and insulator domains in heating and cooling processes, i.e., insulator-metal and metal-insulator transitions, respectively, occurs preferentially at defect sites, such as grain boundaries, surfaces, impurity atoms, vacancies, and dislocations. Since the probability of IMT and MIT depends on the availability of a suitable nucleating defect in the sample space, a rapid temperature sweep, and/or minimization of the sample volume causes a kinetic avoidance of the first-order transition. Naturally, the defects would have preferentially interact with an embryo of a growing metal/insulator domain in order to overcome an activation barrier toward nucleation. During a temperature sweep, the phase-transition kinetics competes with the

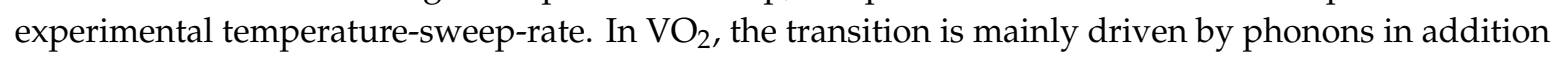
to a contribution from electrons [51]. When the temperature-sweep-rate exceeds the phase-transition 
kinetics, the thermal dynamic motions of $\mathrm{V}$ and $\mathrm{O}$ atoms leading multiple nucleation at latent defect cites are suppressed, and eventually a transition occurs at an energetically preferential defect site. On the other hand, when the temperature-sweep-rate is sufficiently low, the phase transition is fully completed even at latent defect sites.

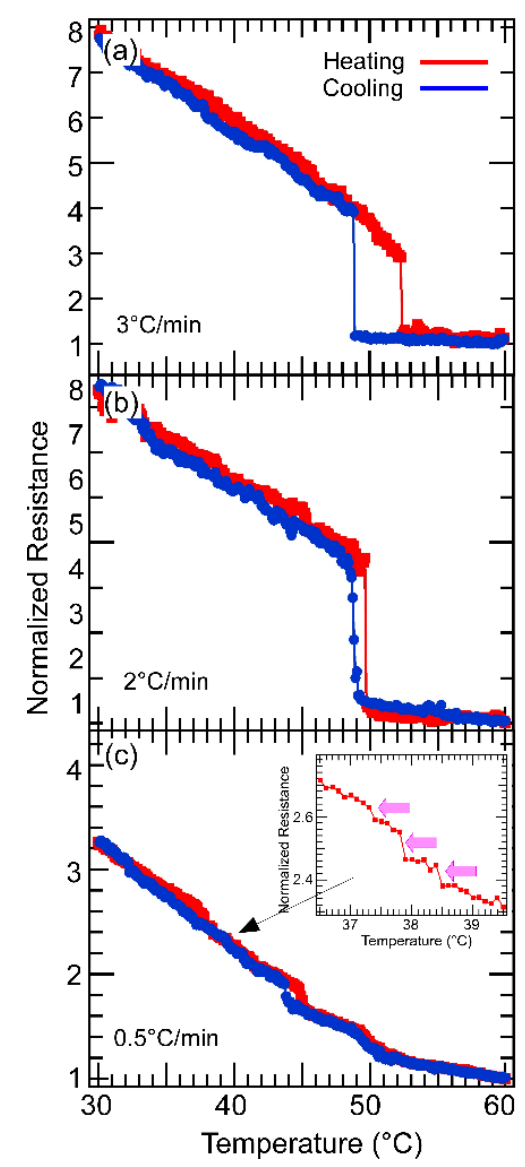

Figure 6. Normalized $R$-T curves for the $\mathrm{VO}_{2}$ wire with $20 \mathrm{~nm}$-gap-electrodes measured at temperaturesweep-rates of (a) $3{ }^{\circ} \mathrm{C} / \mathrm{min}$, (b) $2{ }^{\circ} \mathrm{C} / \mathrm{min}$, and (c) $0.5^{\circ} \mathrm{C} / \mathrm{min}$. Magnified step changes (indicated by arrows) are shown in the insets of (c).

The nucleation rate dependency and corresponding resistivity behavior have been observed as the size effects in the phase transition. In the phase transition of $\mathrm{VO}_{2}$, the size effects have been typically reported for nano-particle systems; these effects originate from size-dependent thermal dissipation [39,41,52-55]. The decreasing domain size consequently induces the shifts of $T_{I \rightarrow M}$ and $T_{M \rightarrow I}$. An increase in the rate of effective thermal exchange in the nano-scale sample leads to a lower (higher) $T_{I \rightarrow M}\left(T_{M \rightarrow I}\right)$. Additionally, the increase in hysteresis width in the $R$ - $T$ curve for a sample consisting of smaller nano-particles [41] implies that a wider $T_{I \rightarrow M}$ and $T_{M \rightarrow I}$ distribution corresponds to a larger numbers of available defect sites in the sample. The temperature-sweep-rate dependent behavior of the step changes in resistivity in the nano-confined $\mathrm{VO}_{2}$ sample (Figure 6) clearly reveals the increases in $N_{D}$ and $T_{I \rightarrow M}$ and $T_{M \rightarrow I}$ variation in addition to the shift of $T_{\text {center. }}$.

The statistical transition model based on the observed results for a spatially confined sample can adequately explain and seamlessly assign the complex domain dynamics in phase-separated $\mathrm{VO}_{2}$ from the micro-scale to the macro-scale. When the sample size increases from the micro-scale $\left(\sim D_{\text {ave }}\right)$ to the macro-scale $\left(>>D_{\text {ave }}\right)$, the $N_{D}$ of the sample drastically increases. For example, $N_{D}$ was estimated to be a few hundreds in a $2 \times 2 \mu \mathrm{m}^{2} \mathrm{VO}_{2}$ sample $(W=2 \mu \mathrm{m}$ and $L=2 \mu \mathrm{m})$. This sample showed a gradual $R-T$ curve without any step changes, which means that the contribution of each domain 
is buried and is not detectable in larger sample. Actually, we observed the temperature-sweep-rate dependence as a slight temperature shift. In this sample, $T_{I \rightarrow M}$ reduction was confirmed, while $T_{M \rightarrow I}$ was insensitive to the temperature-sweep-rate, which reflects the structural stability of $\mathrm{VO}_{2}$ phases. The low-temperature monoclinic phase is energetically favored over the high-temperature rutile phase [49], and the MIT requires a larger driving forces than the IMT in order to overcome the nucleation barrier in $\mathrm{VO}_{2}$ [41]. $T_{I \rightarrow M}$ was reduced to $2-3^{\circ} \mathrm{C}$ in the $2 \times 2 \mu \mathrm{m}^{2} \mathrm{VO}_{2}$ sample when the temperature-sweep-rate was changed from $3{ }^{\circ} \mathrm{C} / \mathrm{min}$ to $0.5^{\circ} \mathrm{C} / \mathrm{min}$. According to the IMT statistical model with a random resistor network, the $T_{I \rightarrow M}$ increase of $2-3{ }^{\circ} \mathrm{C}$ was ascribed to the 20-100-fold increase in $N_{D}$ under a constant $T_{\text {center }}$. The $T_{I \rightarrow M}$ increase may be cause by the decrease of $P_{C}$. It was reported the critical fraction value: $P_{C}$ depends on the $N_{D}$ and arrangement of the metallic (insulating) domains in a sample $[26,27]$. That means the degree of the changing ratio, i.e., the shape of the $R$ - $T$ curve (one-step, multi-steps, and gradual changes) depends on the $N_{D}$; the changing ratio and sharpness is enhanced with decreasing $N_{D}$. Additionally, the decrease of $N_{D}$ enhances the contribution of each single domain to the total change in the $R-T$ curve. Therefore, the 20-100-fold increase in $N_{D}$ caused the corresponding $\sim 4-10$-fold reduction in domain size associated with the $2-3{ }^{\circ} \mathrm{C}$ increase in $T_{I \rightarrow M}$, which is consistent with previous studies $[41,53]$.

\section{Conclusions}

The domain dynamics in phase-separated $\mathrm{VO}_{2}$ was systematically studied. To identify the single-domain IMT and MIT behavior, a spatially confined $\mathrm{VO}_{2}$ sample was prepared. The step changes in the resistivity of a nano-confined sample, which are absent in macrosize $\mathrm{VO}_{2}$ samples, correspond to the first-order IMT and IMT from a single domain and the distributed $T_{I \rightarrow M}$ and $T_{M \rightarrow I}$. Changing the temperature-sweep-rate led to the variation of the transition behavior corresponding to nucleation events. As a result of the competition between the phase-transition kinetics and the experimental temperature-sweep-rate, a realistic domain size and their $T_{I \rightarrow M}$ and $T_{M \rightarrow I}$ were decided. We proposed a statistical transition model, where the macroscopic transition behavior, i.e., an observable $R-T$, was reproduced using the one-step $R$ - $T$ curve for a single domain, the total number of domains in the sample, and their $T_{I \rightarrow M}$ and $T_{M \rightarrow I}$ distribution. In the frame of the statistical transition model, the phase-separation scenario and temperature-sweep-rate-dependent behavior were able to be explained quantitatively. The advantage of studying a nano-confined sample is the quantification of the domain generation (nucleation) process. The number of the step changes in an $R$ - $T$ curve and their temperature distribution indicate $N_{D}$ and $T_{I \rightarrow M}$ and $T_{M \rightarrow I}$ distribution. Direct understanding of the statistical IMT and MIT properties of electronic domains in the nano-confined sample can advance the detailed physics of phase transition. Furthermore, the number of domains can be controlled by designing the sample structure, i.e., confinement effect. The arbitrary control of $N_{D}$ and $T_{I \rightarrow M}$ and $T_{M \rightarrow I}$ temperature distribution would lead to a preferential response, which can be a good guideline for realizing the functional nanoelectronic devices based on the phase-separated CEMs.

Author Contributions: Conceptualization, A.N.H. and H.T.; sample fabrication, A.N.H., A.I.O., and Y.N.; data curation, A.N.H., A.I.O., and K.H.; writing-original draft preparation, A.N.H.; writing-review and editing, A.I.O., K.H., Y.N., H.S., H.A., and H.T.; scientific discussion and project administration, A.N.H.; funding acquisition, A.N.H. and H.T.; All authors have read and agreed to the published version of the manuscript.

Funding: This research was funded by JSPS KAKENHI (Scientific Research B (Nos. 18H01871 and 20H02483), Scientific Research A (No. 17H01054), and Grant-in-aid for Young Scientists (20K15116)), A-STEP from JST (No. JPMJTM19CM) and by the Dynamic Alliance for Open Innovation Bridging Human, Environment and Materials of the Network Joint Research Center for Materials and Devices (Nos. 2015352 and 20203017), Kansai Research Foundation for Technology Promotion, TEPCO Memorial Foundation, SEI Group CSR Foundation, Futaba Research Grant Program of the Futaba Electronics Memorial Foundation.

Acknowledgments: The authors thank Saeko Tonda and Shouichi Sakakihara (ISIR, Osaka Univ.) for their helpful support for the sample preparation. The authors also thank Shouhei Katao (NAIST) for his assistance in XRD measurements. This work was also partly supported by the Nanotechnology Platform Projects (Nanotechnology Open Facilities in Osaka University, and Synthesis of Molecules and Materials in NAIST) of MEXT, Japan (Grant Nos. JPMXP09F20OS0008 and JPMXP09S20OS0006). 
Conflicts of Interest: The authors declare no conflict of interest.

\section{References and Note}

1. Morin, E.J. Oxides Which Show a Metal-to-Insulator Transition at the Neel Temperature. Phys. Rev. Lett. 1959, 3, 34. [CrossRef]

2. Eyert, V. The metal-insulator transitions of $\mathrm{VO}_{2}$ : A band theoretical approach. Ann. Phys. 2002, 11, 650-702. [CrossRef]

3. Yang, Z.; Ko, C.; Ramanathan, S. Oxide Electronics Utilizing Ultrafast Metal-Insulator Transitions. Annu. Rev. Mater. Res. 2011, 41, 337-367. [CrossRef]

4. Cavalleri, A.; Tóth, C.; Siders, C.W.; Squier, J.A.; Raksi, F.; Forget, P.; Kieffer, J.C. Femtosecond Structural Dynamics in $\mathrm{VO}_{2}$ during an Ultrafast Solid-Solid Phase Transition. Phys. Rev. Lett. 2001, 87, 237401. [CrossRef] [PubMed]

5. Kübler, C.; Ehrke, H.; Huber, R.; Lopez, R.; Halabica, A.; Haglund, R.F.; Leitenstorfer, A. Coherent Structural Dynamics and Electronic Correlations during an Ultrafast Insulator-to-Metal Phase Transition in $\mathrm{VO}_{2}$. Phys. Rev. Lett. 2007, 99, 116401. [CrossRef]

6. Kim, H.-T.; Chae, B.-G.; Youn, D.-H.; Maeng, S.-L.; Kim, G.; Kang, K.-Y.; Lim, Y.-S. Mechanism and Observation of Mott Transition in $\mathrm{VO}_{2}$-Based Two- and Three-Terminal Devices. New J. Phys. 2004, 6, 52. [CrossRef]

7. Stefanovich, G.; Pergament, A.; Stefanovich, D. Electronical Switching and Mott Transition in $\mathrm{VO}_{2}$. J. Phys. Condens. Matter 2000, 12, 8837-8845. [CrossRef]

8. Strelcov, E.; Lilach, Y.; Kolmakov, A. Gas Sensor Based on Metal-Insulator Transition in $\mathrm{VO}_{2} \mathrm{Nanowire}$ Thermistor. Nano Lett. 2009, 9, 2322-2326. [CrossRef]

9. Yajima, T.; Nishimura, T.; Toriumi, T. Positive-bias gate-controlled metal-insulator transition in ultrathin $\mathrm{VO}_{2}$ channels with $\mathrm{TiO}_{2}$ gate dielectronics. Nat. Commun. 2015, 6, 1-9. [CrossRef]

10. Pellegrino, L.; Manca, N.; Kanki, T.; Tanaka, H.; Biasotti, M.; Bellingeri, E.; Siri, A.S.; Multistate, D. Multistate Memory Devices Based on Free-Standing $\mathrm{VO}_{2} / \mathrm{TiO}_{2}$ Microstructures Driven by Joule Self-Heating. Adv. Mater. 2012, 24, 2929-2934. [CrossRef]

11. Shukla, N.; Thathachary, A.V.; Agrawal, A.; Paik, H.; Aziz, A.; Schlopp, D.G.; Gupta, S.K.; Engel-Herbert, R.; Datta, S. A Steep-Slope Transistor Based on Abrupt Electronic Phase Transition. Nat. Commun. 2015, 6, 1-6. [CrossRef] [PubMed]

12. IEEE. The International Roadmap for Devices and Systems. 2020. Available online: https://irds.iee.org/ (accessed on 7 July 2020).

13. Tsuji, Y.; Kanki, T.; Murakami, Y.; Tanaka, H. Single-step metal-insulator transition in thin film-based vanadium dioxide nanowires with a $20 \mathrm{~nm}$ electrode gap. Appl. Phys. Express 2019, 12, 025003. [CrossRef]

14. Ueda, H.; Kanki, T.; Tanaka, H. Manipulation of metal-insulator transition characteristics in aspect ratio-controlled $\mathrm{VO}_{2}$ micro-scale thin films on $\mathrm{TiO}_{2}$ (001) substrates. Appl. Phys. Lett. 2013, 102, 153106. [CrossRef]

15. Qazilbash, M.M.; Brehm, M.; Chae, B.G.; Ho, P.C.; Andreev, G.O.; Kim, B.J.; Yun, S.J.; Balatsky, A.V.; Maple, M.B.; Keilmann, F.; et al. Mott Transition in $\mathrm{VO}_{2}$ Revealed by Infrared Spectroscopy and Nano-Imaging. Science 2007, 318, 1750-1753. [CrossRef]

16. He, X.; Xu, T.; Xu, X.; Zeng, Y.; Xu, J.; Sun, L.; Wang, C.; Xing, H.; Wu, B.; Lu, A.; et al. In Situ Atom Scale Visualization of Domain Wall Dynamics in $\mathrm{VO}_{2}$ Insulator-Metal Phase Transition. Sci. Rep. 2015, 4, 6544. [CrossRef]

17. Takami, H.; Kawatani, K.; Ueda, H.; Fujiwara, K.; Kanki, T.; Tanaka, H. Tuning metal-insulator transition by one dimensional alignment of giant electronic domains in artificially size-controlled epitaxial $\mathrm{VO}_{2}$ wires. Appl. Phys. Lett. 2012, 101, 263111. [CrossRef]

18. Tsubota, S.; Hattori, A.N.; Nakamura, T.; Azuma, Y.; Majima, Y.; Tanaka, H. Enhancement of discrete changes in resistivity in engineered $\mathrm{VO}_{2}$ heterointerface nanowall wire. Appl. Phys. Express 2017, 10, 115001. [CrossRef]

19. Kawatani, K.; Kanki, T.; Tanaka, H. Formation mechanism of a microscale domain and effect on transport properties in strained $\mathrm{VO}_{2}$ thin films on $\mathrm{TiO}_{2}$ (001). Phys. Rev. B 2014, 90, 054203. [CrossRef] 
20. Kawatani, K.; Takami, H.; Kanki, T.; Tanaka, H. Metal-insulator transition with multiple micro-scaled avalanches in $\mathrm{VO}_{2}$ thin film on $\mathrm{TiO}_{2}$ (001) substrates. Appl. Phys. Lett. 2012, 100, 173112. [CrossRef]

21. Wu, J.; Gu, Q.; Guiton, B.S.; Leom, N.P.; Ouyang, L.; Park, H. Strain-Induced Self Organization of Metal-Insulator Domains in Single-Crystalline $\mathrm{VO}_{2}$ Nanobeams. Nano Lett. 2006, 6, 2313-2317. [CrossRef]

22. Wu, J.; Gu, Q.; Guiton, B.S.; Leon, N.P.; Ouyang, L.; Park, H. Surface-Stress-Induced Mott Transition and Nature of Associated Spatial Phase Transition in Single Crystalline $\mathrm{VO}_{2}$ Nanowires. Nano Lett. 2009, 9 , 3392-3397.

23. Zhang, S.; Chou, J.Y.; Lauhon, L.J. Direct Correlation of Structural Domain Formation with the Metal Insulator Transition in a $\mathrm{VO}_{2}$ Nanobeam. Nano Lett. 2009, 9, 4527-4532. [CrossRef] [PubMed]

24. Cao, J.; Ertekin, E.; Srinivasan, V.; Fan, W.; Huang, S.; Zheng, H.; Yim, J.W.L.; Khanal, D.R.; Ogletree, D.F.; Grossman, J.C.; et al. Strain engineering and one-dimensional organization of metal-insulator domains in single-crystal vanadium dioxide beams. Nat. Nanotechnol. 2009, 4, 732-737. [CrossRef] [PubMed]

25. Cao, J.; Fan, W.; Zheng, H.; Wu, J. Thermoelectronic Effect across the Metal-Insulator Domain Walls in $\mathrm{VO}_{2}$ Microbeams. Nano Lett. 2009, 9, 4001-4006. [CrossRef] [PubMed]

26. Tanaka, H.; Takami, H.; Kanki, T.; Hattori, A.N.; Fujiwara, K. Artificial three dimensional oxide nanostructures for high performance correlated oxide nanoelectronics. Jpn. J. Appl. Phys. 2014, 53, 05FA10. [CrossRef]

27. Kanki, T.; Kawatani, K.; Takami, H.; Tanaka, H. Direct observation of giant metallic domain evolution driven by electric bias in $\mathrm{VO}_{2}$ thin films on $\mathrm{TiO}_{2}$ (001) substrate. Appl. Phys. Lett. 2012, 101, 243118. [CrossRef]

28. Sohn, A.; Kanki, T.; Sakai, K.; Tanaka, H.; Kim, D.-W. Fractal Nature of Metallic and Insulating Domain Configurations in $\mathrm{VO}_{2}$ Thin Film Revealed by Kelvin Probe Force Microscopy. Sci. Rep. 2015, 5, 10417. [CrossRef]

29. Dagotto, E.; Hotta, T.; Moreo, A. Colossal magnetoresistant materials: The key role of phase separation. Phys. Rep. 2001, 344, 1-153. [CrossRef]

30. Uehara, M.; Mori, S.; Chen, C.H.; Cheong, S.-W. Percolative phase separation underlies colossal magnetoresistance in mixed-valent manganites. Nature 1999, 399, 560-563. [CrossRef]

31. Ward, T.Z.; Liang, S.; Fuchigami, K.; Yin, L.F.; Dagotto, E.; Plummer, E.W.; Shen, J. Reemergent Metal-Insulator Transitions in Manganites Exposed with Spatial Confinement. Phys. Rev. Lett. 2008, 100, 247204. [CrossRef]

32. Preziosi, D.; Lopez-Mir, L.; Li, X.; Cornelissen, T.; Lee, J.H.; Trier, F.; Bouzehouane, K.; Valencia, S.; Gloter, A.; Barthélémy, A.; et al. Direct Mapping of Phase Separation across the Metal-Insulator Transition of $\mathrm{NdNiO}_{3}$. Nano Lett. 2018, 18, 2226-2232. [CrossRef] [PubMed]

33. Mattoni, G.; Zubko, P.; Maccherozzi, F.; Torren, A.J.H.; Boltje, D.B.; Hadjimichael, M.; Manca1, N.; Catalano, S.; Gibert, M.; Liu, Y.; et al. Striped nanoscale phase separation at the metal-insulator transition of heteroepitaxial nickelates. Nat. Commun. 2016, 93, 1-7. [CrossRef] [PubMed]

34. Lee, J.H.; Trier, F.; Cornelissen, T.; Preziosi, D.; Bouzehouane, K.; Fusil, S.; Valencia, S.; Bibes, M. Imaging and Harnessing Percolation at the Metal-Insulator Transition of $\mathrm{NdNiO}_{3}$ Nanogaps. Nano Lett. 2019, 19, 7801-7805. [CrossRef] [PubMed]

35. Hattori, A.N.; Fujiwara, Y.; Fujiwara, K.; Nguyen, T.V.A.; Nakamura, T.; Ichimiya, M.; Ashida, M.; Tanaka, H. Identification of Giant Mott Phase Transition of Single Electronic Nanodomain in Manganite nanowall wire. Nano Lett. 2015, 15, 4322-4328. [CrossRef] [PubMed]

36. Rakshit, R.; Hattori, A.N.; Naitoh, Y.; Shima, H.; Akinaga, H.; Tanaka, H. Three-dimensional Nanoconfinement Supports Verwey Transition in $\mathrm{Fe}_{3} \mathrm{O}_{4}$ Nanowire at $10 \mathrm{~nm}$ length scale. Nano Lett. 2019, 19, 5003-5010. [CrossRef]

37. Fan, W.; Cao, J.; Seidel, J.; Gu, Y.; Yim, J.W.; Barrett, C.; Yu, K.M.; Ji, J.; Ramesh, R.; Chen, L.Q.; et al. Large kinetic asymmetry in the metal-insulator transition nucleated at localized and extended defects. Phys. Rev. B 2011, 83, 235102. [CrossRef]

38. Wei, J.; Wang, Z.; Chen, W.; Cobden, D.H. New aspects of the metal-insulator transition in single-domain vanadium dioxide nanobeams. Nat. Nanotechnol. 2009, 4, 420-424. [CrossRef]

39. Yoon, J.; Kim, H.; Chen, X.; Tamura, N.; Mun, B.S.; Park, C.; Ju, H. Controlling the Temperature and Speed of the Phase Transition of $\mathrm{VO}_{2}$ Microcrystals. ACS Appl. Mater. Interfaces 2016, 8, 2280-2286. [CrossRef]

40. Oike, H.; Suda, M.; Kamitani, M.; Ueda, A.; Mori, H.; Tokura, Y.; Yamamoto, H.M.; Kagawa, F. Size effects on supercooling phenomena in strongly correlated electron systems: $\operatorname{IrTe}_{2}$ and $\theta-(\text { BEDT-TTF })_{2} \operatorname{RbZn}(\mathrm{SCN})_{4}$. Phys. Rev. B 2018, 97, 085102. [CrossRef] 
41. Lopez, R.; Haynes, T.E.; Boatner, L.A. Size effects in the structural phase transition of $\mathrm{VO}_{2}$ nanoparticles. Phys. Rev. B 2002, 65, 224113. [CrossRef]

42. Naitoh, Y.; Tsukagoshi, K.; Murata, K.; Mizutani, W. A Reliable Method for Fabricating sub-10 nm Gap Junctions Without Using Electron Beam Lithography. E-J. Surf. Sci. Nanotechnol. 2003, 1, 41-44. [CrossRef]

43. Bollobas, B. Modern Graph Theory (Graduate Texts in Mathematics); Springer: Berlin, Germany, 1998.

44. Okimura, K.; Sakai, J. Changes in Lattice Parameters of $\mathrm{VO}_{2}$ Films Grown on c-Plane $\mathrm{Al}_{2} \mathrm{O}_{3}$ Substrates across Metal-Insulator Transition. Jpn. J. Appl. Phys. 2009, 48, 045504. [CrossRef]

45. Kawakubo, T.; Nakagawa, T. Phase Transition in $\mathrm{VO}_{2}$. J. Phys. Soc. Jpn. 1964, 19, 517-519. [CrossRef]

46. Peggs, I.P. Thermal Expansion 6; Plenum Press: New York, NY, USA, 1978; pp. 191-201.

47. Yang, Y.; Lee, K.; Zobel, M.; Maćković, M.; Unruh, T.; Spiecker, E.; Schmuki, P. Formation of Highly Ordered $\mathrm{VO}_{2}$ Nanotubular/Nanoporous Layers and Their Supercooling Effect in Phase Transitions. Adv. Mater. 2012, 24, 1571-1575. [CrossRef] [PubMed]

48. In the simulation in Figs. $5(\mathrm{c}-\mathrm{e}),=8{ }^{\circ} \mathrm{C}, T_{\text {center }}=77^{\circ} \mathrm{C}$ in heating (IMT) process and $=9{ }^{\circ} \mathrm{C}, T_{\text {center }}=65^{\circ} \mathrm{C}$ in the cooling (MIT) process were used.

49. Kagawa, F.; Oike, H. Quenching of Charge and Spin Degrees of Freedom in Condensed Matter. Adv. Mater. 2017, 29, 1601979. [CrossRef]

50. Debenedetti, P.G.; Stillinger, F.H. Supercooled liquids and the glass transition. Nature 2001, 410, $259-267$. [CrossRef]

51. Mellan, T.A.; Wang, H.; Schwingenschlögl, U.; Crau-Crespo, R. Origin of the transition entropy in vanadium dioxide. Phys. Rev. B 2019, 99, 064113. [CrossRef]

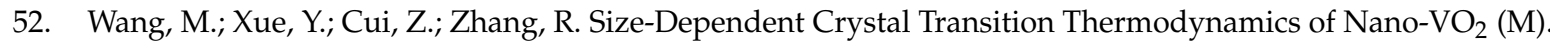
J. Phys. Chem. C 2018, 122, 8621-8627. [CrossRef]

53. Whittaker, L.; Jaye, C.; Fu, Z.; Fischer, D.A.; Banerjee, S. Depressed Phase Transition in Solution-Grown $\mathrm{VO}_{2}$ Nanostructure. J. Am. Chem. Soc. 2009, 131, 8884-8894. [CrossRef]

54. Chena, S.; Ma, H.; Dai, J.; Yi, X. Nanostructured vanadium dioxide thin films with low phase transition temperature. Appl. Phys. Lett. 2007, 90, 101117. [CrossRef]

55. Dai, L.; Cao, C.; Gao, Y.; Luo, H. Synthesis and phase transition behavior of undoped $\mathrm{VO}_{2}$ with a strong nano-size effect. Sol. Energy Mater. Sol. Cells 2011, 95, 712-715. [CrossRef]

(C) 2020 by the authors. Licensee MDPI, Basel, Switzerland. This article is an open access article distributed under the terms and conditions of the Creative Commons Attribution (CC BY) license (http://creativecommons.org/licenses/by/4.0/). 